\title{
Danilo Cruz Vélez y la superación de la metafísica de la subjetividad
}

\author{
Manuel Leonardo Prada Rodríguez ${ }^{*}$ \\ Universidad Santo Tomás
}

Recibido: 25 de noviembre de 2009 A Aprobado: 10 de diciembre de 2009

\section{esumen}

Danilo Cruz Vélez valora el intento de Edmund Husserl de liberar a la filosofía de todos los supuestos, específicamente de la creencia cotidiana en la existencia del mundo, también conocida como tesis general de la actitud natural. Para Edmund Husserl, el punto de partida de la filosofía es la negación de dicha tesis, la epojé, que posibilita la vuelta del yo a sí mismo, erigiéndolo, tal como lo hizo la duda metódica de René Descartes siglos atrás, como lo único verdadero en lo cual se puede fundamentar todo lo que hay. Es esto último lo que, precisamente, más critica Danilo Cruz Vélez, que el padre de la fenomenología no se dio cuenta del supuesto principal en el cual estaba todavía inmerso: la metafísica de la subjetividad. De ahí que el filósofo caldense exponga el pensamiento de su maestro, Martin Heidegger, el cual no despreció la actitud natural, sino que la valoró como punto de partida del filosofar. Desde esa diferencia, según Danilo Cruz Vélez, el filósofo de la Selva Negra logró superar la metafísica de la subjetividad, al no usar el concepto de representación, tan ligado a la vista, sino al proponer el concepto de utilización de, valga la redundancia, útiles, más ligado a la mano. La cuestión es: ¿logró salir Martin Heidegger, realmente, de la metafísica de la subjetividad?

Palabras clave: actitud natural, epojé, metafísica de la subjetividad, representación, útil.

\footnotetext{
* Manuel Leonardo Prada Rodríguez es aspirante al título de Magíster en Filosofía Latinoamericana de la Universidad Santo Tomás. La investigación que adelanta tiene que ver con la mirada que Danilo Cruz Vélez tenía acerca de la metafísica de la subjetividad, la técnica actual y la amenaza que esta última proporciona al ser del hombre y al ecosistema mundial. Correo electrónico: manueco7@gmail.com
} 


\section{Danilo Cruz Vélez and the overcoming of the metaphysics of subjectivity}

\section{Abstract}

Danilo Cruz Vélez appreciates the attempt made by Edmund Husserl to free the philosophy from all suppositions, specifically for everyday belief in the existence of the world, also known as a general thesis of the natural attitude. For Edmund Husserl, the starting point of philosophy is the negation of that thesis, epojé, allowing the return of self to self erecting, as it as done by René Descartes methodical doubt of centuries ago, as the only true in which you can substantiate everything. It is the latter that precisely Danilo Cruz Vélez more criticism, that the father of phenomenology did not realize the main course which was still submerged: the metaphysics of subjectivity. Hence the caldense philosopher expose the thought of his teacher, Martin Heidegger, who did not despise the natural attitude, but who rated it as a starting point for philosophizing. From this difference, according to Danilo Cruz Vélez, the philosopher of the Black Forest was able to overcome the metaphysics of subjectivity, by not using the concept of representation, so linked to sight but to propose the concept of use of, forgive the repetition, useful, more connected to the hand. The question is: Martin Heidegger managed to get really, of the metaphysics of subjectivity?

Key words: natural attitude epojé, metaphysics of subjectivity, representation, useful. 


\section{Danilo Cruz Velez et la supération de la métaphysique}

\section{Résumé}

Danilo Cruz Vélez considére les essais d’Edmund Husserls de libérer la philosophie de toutes les hypothèses, spécifiquement de la croyance quotidienne sur l'existence du monde, connu aussi comme thèse générale de l'actitude naturelle. Pour Edmund Husserl, le point de départ de la philosophie est la négation de cette thèse, "I'épojé" qui rend possible le retour au moi, en soi en le mettant comme le conçoit Descartes plusieurs siècles antérieurs, comme étant l'unique vérité sur laquelle on peut justifier tout ce qui existe. C'est ce dernier aspect que Danilo Cruz critique le plus, en ce qui concerne le père de la phénoménologie, Edmund Husserl, qui ne s'est pas rendu compte de I'hypothèse principal dans lequel il était submergé:"la métaphysique de la subjectivité. A partir de cette position Danilo Cruz expose la pensée de Martin Hiedegger et lui , il n'a pas méprisé l'actitude naturelle il a plutôt apprécié l'activité de philosopher comme point de départ. A partir de cette différence, le philosohpe de la "Selva Negra" arrive à surpasser la métaphysique de la subjectivité pour n'avoir pas utilisé le concept de réprésentation, si lié à la vue, mais aussi sa proposition sur le concept de l'utilisation de l'util beaucoup plus lié avec la main. Posons la question suivante: Martin Heidegger, a-t- il vraiment réussi à se libérer de la métaphysique de la subjectivité?

Mots clés: actitude naturelle, "epojé", métaphysique, de la subjectivité, représentation, I 'util. 


\section{Introducción}

Al leer este artículo, el lector podrá pensar que no versa sobre Danilo Cruz Vélez sino sobre la mirada que Martin Heidegger tenía acerca de la metafísica de la subjetividad y de su máxima expresión: la fenomenología husserliana. Pues bien, el libro de más rigor filosófico que escribió el filósofo colombiano trata justamente de dicha mirada heideggeriana. Es recurrente que Danilo Cruz Vélez exponga el pensamiento de Martin Heidegger como si se tratara de su propio pensamiento. Lejos de ser un plagio, con sus explicaciones el discípulo de Martin Heidegger busca presentar con fidelidad el pensamiento de su maestro. Ese es uno de sus grandes intereses, así como tratar los temas que también le preocuparon a Martin Heidegger, tales como la técnica moderna que amenaza al ser del hombre y el papel del intelectual en esta época, en donde normalmente los intelectuales prefieren escribir textos sin mayor profundidad, con el ánimo de que las editoriales vendan sus publicaciones. Por lo anterior, se aclara que las explicaciones de este artículo acerca del pensamiento de Edmund Husserl y Martin Heidegger están directamente relacionadas con el pensamiento de Danilo Cruz Vélez, expuesto en su libro más importante: Filosofía sin supuestos. Al filósofo caldense le interesa criticar, como lo hizo su maestro, la metafísica de la subjetividad. Y, por supuesto, le encanta afirmar que Martin Heidegger superó la metafísica de la subjetividad. Pero, ¿realmente la superó?

\section{De Husserl a Heidegger: superación, según Danilo Cruz Vélez, de la metafísica de la subjetividad}

Uno de los propósitos de Filosofía sin supuestos es explicar en qué consiste la metafísica de la subjetividad. Para ello, el autor toma como ejemplo la fenomenología de Edmund Husserl. Considera que no es necesario investigar a cada uno de los filósofos de la metafísica de la subjetividad sino al, según él, último representante de dicha tradición. Claro que, durante todo el libro, Danilo Cruz Vélez se empeña en mostrar la deuda que el pensamiento husserliano tiene con el cartesiano. Otro de los propósitos es "ayudar al iniciado en filosofía a dar el paso de Husserl a Heidegger, el acontecimiento más 
importante en el seno de la filosofía del siglo XX" (Cruz Vélez, 2001, p. vii). Y donde mejor se manifiesta ese paso, el momento más vistoso en el cual Martin Heidegger se distancia de su maestro, es en el punto de partida de la filosofía. Ambos coinciden en que la actitud natural es el punto desde el cual se debe partir para comenzar a filosofar. Pero cada uno ve dicha actitud de una manera diferente. Es ese diferente punto de vista el que le permite a Martin Heidegger, según Danilo Cruz Vélez, salir de la metafísica de la subjetividad. Para Edmund Husserl, el ideal es alcanzar una ciencia exenta de supuestos, para poder llegar al yo puro, libre de toda contaminación mundana (para Martin Heidegger, el ideal es alcanzar una filosofía -no una ciencia- libre del supuesto del yo). O sea, un yo libre de esa creencia que las personas tenemos normalmente, de que el mundo existe realmente. Ese ideal proviene, según Danilo Cruz Vélez, del aprecio que Edmund Husserl tenía por la filosofía cartesiana, especialmente por la duda metódica. ¿En qué consiste esa actitud natural?

René Descartes inicia su segunda meditación metafísica diciendo que:

He sido arrojado a tan grandes dudas por la meditación de ayer, que ni puedo dejar de acordarme de ellas ni sé de qué modo han de solucionarse; por el contrario, como si hubiera caído en una profunda vorágine, estoy tan turbado que no puedo ni poner pie en lo más hondo ni nadar en la superficie. Me esforzaré, sin embargo, en adentrarme de nuevo por el mismo camino que ayer, es decir, en apar-tar todo aquello que ofrece algo de duda, por pequeña que sea, de igual modo que si fuera falso; y continuaré así hasta que conozca algo cierto, o al menos, si no otra cosa, sepa de un modo seguro que no hay nada cierto... ¿Cómo sé que no hay nada diferente de lo que acabo de mencionar, sobre lo que no haya ni siquiera ocasión de dudar? ¿No existe algún Dios, o como quiera que le llame, que me introduce esos pensamientos? Pero, ¿por qué he de creerlo, si yo mismo puedo ser el promotor de aquéllos? ¿Soy, por lo tanto, algo? Pero he negado que yo tenga algún sentido o algún cuerpo; dudo, sin embargo, porque, ¿qué soy en ese caso? ¿Estoy de tal manera ligado al cuerpo y a los sentidos, que no puedo existir sin ellos? Me he persuadido, empero, de que no existe nada en el mundo, ni cielo ni tierra, ni mente ni cuerpo; ¿no significa esto, en resumen, que yo no existo? Ciertamente existía si me persuadí de algo (Descartes, 1641, p. 16). 
La anterior cita tiene que ver con el camino cartesiano que, según Danilo Cruz Vélez, Edmund Husserl adoptó como punto de partida para filosofar. Sucede que los seres humanos, al relacionarnos con nuestro mundo circundante mediante las representaciones, los juicios, los sentimientos, los valores y las querencias, nos encontramos en una situación prefilosófica. En dicha actitud, el yo no se pone cuidado a sí mismo, sino que sólo le pone cuidado al mundo. En ese estado de enajenación, distracción o falta de atención en nosotros mismos, creemos ingenuamente que dicho mundo existe realmente, como lo explica Danilo Cruz Vélez:

La nota fundamental de los actos es la intencionalidad. Todo acto es intencional, apunta hacia un objeto, tiene un intentum. Según esto, debemos ver los actos ejecutados en actitud natural a la luz de la intencionalidad. ¿En qué consiste, pues, la referencia intencional a las cosas cuando se hace en actitud natural? La referencia en actitud natural tiene el carácter de una intentio recta. En ella el yo va directamente hacia los objetos, sin atender a nada más. El yo se pierde en las cosas y se olvida de sí mismo. En la actitud natural el yo está, pues, olvidado. Las cosas son lo real, lo existente. La actitud natural es precisamente una fe ciega en la realidad de las cosas (Cruz Vélez, 2001, p. 253).

Esta es la tesis general de la actitud natural, en la cual, por voluntad propia, ponemos al mundo como existente (voluntad como aspecto del yo que tiempo después rescatarán Schopenhauer y Nietzsche). Pero, también por voluntad propia, podríamos rechazar esa creencia. Sólo que, si negáramos libremente la existencia del mundo, negaríamos, necesariamente, la existencia del yo, porque este último "consiste en un conjunto de actos intencionales que apuntan a los objetos mundanos" (Cruz Vélez, 2001, p. 18). Por consiguiente, al negar tanto al mundo como al yo que se fija en él, se niega de paso esa relación que hay entre el yo y su mundo circundante. Sin esa relación, no habría ni actitud natural ni nada. Y tal aseveración sería puro escepticismo.

Cuando empleamos la voluntad para afirmar o negar al mundo, estamos suponiendo que es verdad lo que decimos: "es verdad que el mundo existe", o "es verdad que el mundo no existe". Por eso, para Edmund Husserl, lo mejor es no realizar ningún juicio sobre el mundo, ni para afirmarlo ni para negarlo. Es preferible suspender el juicio sobre el mundo: epojé, como 
decían los estoicos. Por eso, sin desconocer que la voluntad es un acto del pensamiento, Edmund Husserl no ve en la voluntad un punto de partida del filosofar. Él, como René Descartes, no quiere eliminar al yo, sino todo lo opuesto: rescatarlo como lo único cierto e indubitable. Por eso, según ambos filósofos, tal como lo muestra la segunda meditación cartesiana, debemos alejarnos de las cosas de las cuales se puede dudar, reconociendo así que no hay nada cierto en el mundo. Lo único que es absolutamente indubitable sólo puede mostrarse cuando ponemos entre paréntesis la existencia de ese mundo incierto e inseguro, cuando ponemos entre paréntesis incluso que tenemos sentidos, que tenemos cuerpo. Al llegar a ese punto tan radical (que no es lo suficientemente radical para Martin Heidegger, porque no alcanza a poner entre paréntesis al yo), podemos quedar convencidos de que nada existe, con excepción de nuestro pensamiento. Pues, si estamos persuadidos o convencidos de algo, eso significa que estamos pensando. $Y$ si estamos pensando algo, entonces estamos siendo, porque lo que no es, no puede pensar ni ser pensado. $Y$ así se retorna a la equiparación hecha por Parménides entre ser y pensar: "Del Ser puede hablarse, al Ser puedo yo hacerlo objeto de mi pensamiento; pero el que yo pueda pensar y hablar del Ser es posible "porque lo mismo es poder ser pensado que poder ser»" (Copleston, 1969, p. 62). Pienso, es decir, soy, como prefiere decir el maestro Luis Eduardo Hoyos:

Seguramente se ha oído hablar de la célebre expresión 'yo pienso, luego yo existo', que en realidad debe ser mejor interpretada como'yo pienso, es decir, yo existo', pues no es correcto comprender que con ella se infiere lógicamente el 'yo existo' a partir del 'yo pienso', sino que, más bien, se señala de forma explícita que el decir'yo pienso' implica siempre que'yo existo', pues si no, no habría alguien que existe cuando piensa, lo cual es absurdo (Hoyos, 2003, p. 21).

Tenemos, entonces, que el yo es lo único seguro e inconmovible por la duda. "Pero el yo no es solamente la única cosa verdadera, sino también la fuente de toda verdad" (Cruz Vélez, 2001, p. 250). Como sabemos, René Descartes no es empirista, sino racionalista, motivo por el cual, para él, en el yo se encuentran las ideas. Pero no al estilo de la teoría de Platón, pues para René Descartes la idea no es el ser de la cosa, no es la figura en la cual el ser se hace patente. Más bien, para el padre de la filosofía moderna, las ideas son cogitaciones 
o pensamientos que se refieren a todas las cosas y determinan su ser. Y si la idea es el pensamiento, y el pensamiento está en el yo, entonces el yo es la permanente presencia en la que las cosas se hacen presentes, en la que las cosas obtienen la determinación de su ser, en la que el ser de las cosas es representado. La subjetividad es, por ende, la dimensión del ser. Por este motivo, "Aquello en que las cosas son, por lo cual ganan presencia, son las re-presentaciones" (Cruz Vélez, 2001, p. 250). Y es en ese campo en donde se mueve Edmund Husserl.

Al poner entre paréntesis la ingenua tesis de que el mundo realmente existe, al desentenderme de la existencia del mundo, tanto la tesis de la actitud natural como el mundo se convierten en fenómenos subjetivos. Esto significa que, en vez de dirigirme al mundo, ahora cambio, libremente, de rumbo. Ahora me dirijo a mí mismo. Le pongo cuidado a ese yo que había olvidado en la actitud natural. Por consiguiente, ese cambio de dirección es un movimiento de regreso del yo a sí mismo, al cual nos referimos como reflexión. Llegamos así, a la subjetividad, que es donde Edmund Husserl, como René Descartes, ubica el campo de la filosofía. De esta manera, se presenta un contraste entre la actitud natural, que es una actitud directa, porque el yo se dirige al mundo, y la actitud filosófica, que es una actitud refleja, porque el yo se dirige hacia sí mismo. Gracias a esa reflexión, la subjetividad, y no el mundo, es la residencia de la verdad. Es decir, debido al movimiento de regreso del yo hacia sí mismo, todo lo que es, es aquello de lo cual se puede hablar, como decía Parménides, según la siguiente explicación hecha por Frederick Copleston, realizada, seguramente, desde el horizonte de la metafísica de la subjetividad:

Ser, sea cual fuere su naturaleza, es, existe, y no puede no ser. Lo Ente es, y le es imposible no ser. Del Ser puede hablarse, al Ser puedo yo hacerlo objeto de mi pensamiento; pero el que yo pueda pensar y hablar del Ser es posible «porque lo mismo es poder ser pensado que poder ser». Mas si «lo Ente» puede ser, luego es. ¿Por qué? Porque si, pudiendo ser, sin embargo no fuese, entonces sería la nada. Ahora bien, la nada no puede ser objeto del habla ni del pensamiento, por cuanto hablar de nada es no hablar, y pensar en nada es no pensar en absoluto (Copleston, 1969, p. 62). 
Así, no se puede hablar de nada que no sea objeto de un acto subjetivo. Nosotros percibimos los objetos trascendentes, o sea, aquella realidad que está afuera de nosotros (como si nosotros realmente fuéramos almas encerradas en un cuerpo, al modo de Platón, del cual no sólo hacemos epojé, del cual no solamente somos indiferentes por un momento, sino del cual nos diferenciamos todo el tiempo. Como si no fuéramos cuerpo). También juzgamos, recordamos, valoramos; cogitamos esos objetos trascendentales. En la metafísica de la subjetividad, el ser de los objetos no se reduce a la percepción, como pensaba George Berkeley, sino que, según la predilección de cada filósofo, el ser de los objetos se manifiesta también en otras cogitaciones. Así por ejemplo, para Nietzsche, el ser de los objetos consiste en la valoración que la voluntad del sujeto les dé, "De modo que su ser es un ser constituido subjetivamente" (Cruz Vélez, 2001, p. 20). Y con esto, nos encontramos con otra contraste: aunque los fenómenos subjetivos -es decir, el mundo y la creencia de que éste existe, las cosas en general, los objetos- son relativos al sujeto, pues son para él; por el contrario, el ser del yo es absoluto, pues es para sí mismo. Por esta misma razón, el yo es el fundamento de todo lo que hay, o sea, de todo (objeto) lo que se presenta en la mente humana (sujeto), mediante la representación, sea ésta una percepción, o un juicio, o una valoración o, como lo explica José Ferrater Mora:

REPRESENTACIÓN. El término 'representación' es usado como vocablo general que puede referirse a diversos tipos de aprehensión de un objeto (intencional). Así, se habla de representación para referirse a la fantasía (VÉASE) (intelectual o sensible) en el sentido de Aristóteles; a la impresión (directa o indirecta), en el sentido de los estoicos; a la presentación (sensible o intelectual, interna o externa) de un objeto intencional, o repraesentatio, en el sentido de los escolásticos; a la reproducción en la conciencia de percepciones anteriores combinadas de varios modos, o phantasma, en el sentido asimismo de los escolásticos; a la imaginación en el sentido de Descartes; a la aprehensión sensible, distinta de la conceptual, en el sentido de Spinoza; a la percepción (v.) en el sentido de Leibniz; a la idea (v.) en el sentido de Locke, Hume y algunos ideólogos; a la aprehensión general, que puede ser intuitiva, conceptual o ideal, de Kant; a la forma del mundo de los objetos como manifestación de la Voluntad, en el sentido de Schopenhauer, etc. (Ferrater Mora, 1965, pp. 566-567). 
Con base en lo anterior, podemos ver lo importantes que son la representación y la reflexión para la metafísica de la subjetividad. Las cosas sólo son cuando son objetos de los actos de la mente, es decir, de las representaciones. Lo cual, visto de otra manera, significa que la mente humana es el fundamento de todas esas cosas que sólo son cuando dicha mente las representa. Pero todo esto se puede hacer en la actitud natural. Es decir, sólo representando objetos del mundo no se puede filosofar. Para llegar a esa cogitación última del pensamiento, hay que dar un paso más allá de la mera representación de objetos mundanos. Hay que llegar a la reflexión. Cuando mi mente deja de dedicarse a representar el mundo para dedicarse a representarse a sí misma, entonces brota la actitud filosófica. Cuando me convierto en objeto de mí mismo, entonces puedo filosofar. El objeto de la filosofía soy yo (¿no es esto una reducción de la filosofía a la filosofía de la mente?).

Y es esto, justamente, lo que Martin Heidegger le critica a la fenomenología husserliana y a las demás manifestaciones de la metafísica de la subjetividad. Según él, para que pueda surgir el filosofar, no es suficiente poner entre paréntesis la tesis general de la actitud natural, esa creencia de que el mundo existe realmente, sino que es necesario también poner entre paréntesis la creencia de que el filosofar surge en la reflexión, en la vuelta del yo hacia sí mismo, cuando deja de contemplar, mediante representaciones, al mundo. Pero, el hecho de que ni Edmund Husserl ni los metafísicos de la subjetividad que lo precedieron descuidaran esa creencia, significa que ellos no se dieron cuenta de que había que dar un paso más allá. Esto es, operaron con el gran supuesto de esa metafísica: el yo, la subjetividad (de ahí viene su nombre). Usaron dicho término sin tematizarlo, sin problematizarlo, sin pensarlo bien sino dándolo por sentado, como un hecho.

Pero, entonces, si no es con ese supuesto, ¿cómo se origina el filosofar?, ¿qué significa poner entre paréntesis la creencia de que el filosofar surge en la reflexión? Como sabemos, los seres humanos no tenemos ciertas limitaciones. No somos como el Dios de la teología occidental, que todo lo sabe de antemano, motivo por el cual no tuvo que aprender nada nunca; ni somos extraterrestres con capacidades epistemológicas diferentes a las del ser humano, que le permitan adquirir el conocimiento de una manera que 
no conocemos ni podemos, por naturaleza, conocer. Somos, sencillamente, seres humanos en el mundo. Eso es todo. Desde la metafísica de la subjetividad, sólo podemos tener certeza de que existimos nosotros, y de que, sin esa certeza, en la actitud natural, existimos en un mundo que cambia todo el tiempo, en un mundo cuya presencia fluye o deviene constantemente. Y no se puede hacer filosofía de lo que cambia, pues eso es lo propio de las ciencias positivas. Sólo se puede hacer filosofía de lo que permanece en el cambio. Esa permanente presencia, para René Descartes y los demás metafísicos de la subjetividad, es la mente humana, que puede abstraer en categorías inmutables ese cúmulo de cambios. En el tiempo y en el espacio, como decía Immanuel Kant, se organizan de una manera estable ese cúmulo de percepciones caóticas que ingresan a la mente a través de los sentidos. Pero, para Martin Heidegger, la permanente presencia no es la mente humana, como se piensa desde la actitud filosófica propia de la metafísica de la subjetividad; ni es el mundo, como se piensa desde la actitud natural. La permanente presencia es, sencillamente, el ser. Y con eso, entonces, el filósofo de la selva negra toma distancia de los filósofos antecesores.

Ahora bien, aunque para Martin Heidegger, mi mente, y sólo mi mente -como decía la metafísica de la subjetividad- no es la permanente presencia, sin embargo, en mi mente, y sólo en mi mente, sí está esa permanente presencia, o, como preferiría decirlo Martin Heidegger, mi mente es en el ser. En la mente humana, y sólo en ella, se da o se manifiesta el ser. El ser no se manifiesta en lo óntico, en las cosas, sino en lo ontológico, en el ente ontológico que es sólo el ser humano. Como lo dice él mismo en el segundo parágrafo de Ser y Tiempo:

En cuanto búsqueda, el preguntar está necesitado de una previa conducción de parte de lo buscado. Por consiguiente, el sentido del ser ya debe estar de alguna manera a nuestra disposición. Como se ha dicho, nos movemos desde siempre en una comprensión del ser... Dirigir la vista hacia, comprender y conceptualizar, elegir, acceder a..., son comportamientos constitutivos del preguntar y, por ende, también ellos, modos de ser de un ente determinado, del ente que somos en cada caso nosotros mismos, los que preguntamos. Por consiguiente, elaborar la pregunta por el ser significa hacer que un ente-el que pregunta- se vuelva transparente en su ser. El planteamiento de esta pregunta, 
como modo de ser de un ente, está, él mismo, determinado esencialmente por aquello por lo que en él se pregunta -por el ser-. A este ente que somos en cada caso nosotros mismos, y que, entre otras cosas, tiene esa posibilidad de ser que es el preguntar, lo designamos con el término Dasein. El planteamiento explícito y transparente de la pregunta por el sentido del ser exige la previa y adecuada exposición de un ente (del Dasein) en lo que respecta a su ser (Heidegger, 1927, pp. 16 -18).

Los seres humanos son, en la filosofía heideggeriana, los únicos que existen. Así, la cosa, el perro, la mesa, el martillo, la montaña, y todos los demás entes ónticos no existen. Sólo existe el ente que es el ahí del ser. Sólo el ser humano (ya en esta expresión se ve cómo está contenido el ser en nuestra propia constitución), que no es meramente óntico (¿no es esto un eco de la platónica diferenciación entre alma y cuerpo?), sino que es ontológico (¿alma?, ¿mente?, ¿espíritu?), es el lugar, por decirlo así, donde se manifiesta el ser. Por eso, en la filosofía heideggeriana, el ser humano es conocido, a secas, como existencia: Da-sein, el ahí del ser, apelativo que no se le puede asignar a ningún otro ente, ni siquiera a Dios, con quien, en la Edad Media, se solía confundir al ser. Básicamente, porque ningún otro ente tiene lenguaje: "También el que no piensa expresamente el ser, está en relación con él en el lenguaje, que piensa siempre por el hombre. En efecto, nosotros decimos, v. gr., 'el árbol es hermoso', y comprendemos el 'es'"' (Heidegger, 1934, pp. 256-257).

Pero el concepto de "ser humano" no se reduce únicamente al concepto de "filósofo". Edmund Husserl y, en general, los demás metafísicos de la subjetividad, consideran a los demás seres humanos como entes ónticos. Prácticamente, los demás seres humanos están al mismo nivel de las cosas. Sólo quienes descuidan por un momento lo óntico, como lo hizo René Descartes mediante su duda metódica, pueden pasar al estado superior de lo ontológico'. Se trata de usar la libertad propia de la voluntad humana, para optar por liberarse de la actitud natural y trascender así al plano superior

1 Algo similar sucede en la teología occidental: si bien es cierto que Dios creó a todos los seres humanos, hay una diferencia notable entre los seres humanos que son simplemente criaturas y los seres humanos que se convierten en hijos de Dios al relacionarse con Él. Diferencia que en la Edad Media recalcaron los cruzados: "nosotros los cristianos versus los moros", y que hoy en día recalcan algunos grupos evangélicos: "nosotros los salvos versus los paganos a los cuales hay que evangelizar". 
de la filosofía. La mayoría de la gente se queda, por consiguiente, como esclava de la actitud natural, como los esclavos del platónico mito de la caverna, y sólo los iluminados, sólo los que salen con esfuerzo intelectual de dicha caverna para ver el sol o idea del bien, sólo quienes se dedican a la vida contemplativa, pueden alcanzar ese estado superior. Mientras que Martin Heidegger, cual Prometeo que roba el fuego de Hefestos, pretende entregarle la filosofía a todos los seres humanos (quienes, curiosamente, siguen ignorando la posesión de ese don divino). Así, para el filósofo de la selva negra, no es mediante una reflexión, tras una puesta entre paréntesis del mundo, que se llega a la filosofía, sino que es poniendo entre paréntesis la reflexión, es decir, retornando al mundo, en donde parte la filosofía. Como lo explica Danilo Cruz Vélez:

Como es obvio, en la superación de la metafísica de la subjetividad Heidegger supera también esta doctrina sobre el origen de la filosofía. La caracterización del hombre como una relación con el ser está allende dicha doctrina. El hombre está en esa relación también en la actitud natural. Aunque no estemos en actitud filosófica, nos movemos siempre dentro de una comprensión del ser, aunque no lo sepamos ni nos hagamos cuestión de ella para elaborar una ontología. Esto es lo que ya conocemos como la comprensión preontológica del ser (Cruz Vélez, 2001, p. 256).

Sin embargo, al estar sumergidos en nuestros quehaceres, lo único que hacemos es operar sobre dicha comprensión preontológica o preconceptual del ser. Es una comprensión tan comprensible, que usualmente no caemos en cuenta de que sería bueno tematizarla. Esa clase de comprensión del ser es necesaria para poder existir. Es necesaria para existir porque por medio de ella atribuimos el ser, el "es", a todos los entes, a todo lo que hay, es decir, sin ella no podríamos referirnos a nada, quizá ni siquiera haciendo señas (pues estas también son parte del lenguaje). Pero, precisamente, a pesar de esa necesidad de usar el verbo "ser", nos olvidamos del ser, nos mantenemos indiferentes ante él. Por causa de esa indiferencia, no sabemos qué es el ser, así lo comprendamos. Y entonces, aquí tenemos que mirar qué significa, según el pensamiento heideggeriano, comprender: 
La disposición afectiva es una de las estructuras existenciales en que se mueve el ser del "Ahí". Este ser está constituido, cooriginariamente con ella, por el comprender [Verstehen]. La disposición afectiva tiene siempre su comprensión, aun cuando la reprima. El comprender es siempre un comprender afectivamente templado. Si lo interpretamos como un existencial fundamental, con ello se muestra que este fenómeno es comprendido como un modo fundamental del ser del Dasein. En cambio, el "comprender" en el sentido de un posible modo de conocimiento entre otros, diferente, por ejemplo, del "explicar", deberá ser interpretado, junto con éste, como un derivado existencial del comprender primario que es constitutivo del ser del Ahí en cuanto tal (Heidegger, 1927, p. 146).

El comprender no es, entonces, simplemente el entender una cosa, pues la comprensión de la cual habla Martin Heidegger no versa sobre una cosa, sino sobre el ser. Y, por cuanto él le da un lugar primordial a la afectividad, por encima del conocimiento, se podría decir que la comprensión preontológica del ser tiene que ver más con el sentir que con el entender. La comprensión es un carácter estructural de la existencia humana, no un acto del pensamiento, al estilo de la representación. Aunque, por supuesto, no excluye al conocimiento. Lo que pasa es que no es el conocimiento mismo, sino la condición ontológica que posibilita al conocimiento. Y con esto se aparta Martin Heidegger de la metafísica de la subjetividad, postulando algo diferente: ante el "pienso, es decir existo", propone el "porque estoy triste, soy" o "amanecí contento y de esa manera aprenderé cómo es mi mundo circundante hasta que mi estado de ánimo cambie". Es un paso desde la razón al sentimiento, a la afectividad. Sólo que, en mi opinión, esto no es ninguna superación. Cambiar el curso de la conversación, colocar un tema diferente, no significa resolver el problema sobre el cual se estaba discutiendo en dicha conversación.

Sigue latente, entonces, el problema de cómo es que conocemos, si por las ideas innatas como decían los racionalistas, si por las experiencias como decían los empiristas, si por los afectos como decía Martin Heidegger. Pero en cualquier caso, quien conoce, sea pensando, experimentando o sintiendo, es un ser humano. ¿Qué diferencia, por tanto, la propuesta de que los seres humanos conocemos a través de la afectividad, de la teoría de que aprendemos por medio de la observación ordinaria y los experimentos? Desde 
mi punto de vista, la única diferencia consiste en el modo de conocer, pero el sujeto cognoscente sigue siendo el mismo. Sigue siendo el sujeto el que siente tristeza. Sigue siendo el yo el que conoce a través de su afectividad, de sus modos de ser en el mundo. Y los útiles siguen siendo útiles para él. Son sólo en la medida en que le sirven, de la misma manera que los objetos son en la medida que son conocidos por el sujeto. Si un objeto o útil no es utilizado por un ser humano, entonces no es. Sólo el Dasein existe. Postura diferente de la que postula a la mente como fundamento de todo lo que hay, pero postura que no es de ninguna manera una salida de la metafísica de la subjetividad. Palabras más, palabras menos, la genialidad de Martin Heidegger consiste en postular al corazón en el lugar que sus predecesores le dieron a la razón.

Pero, retomando el tema que se venía exponiendo antes de manifestar mi opinión personal, y volviendo al ejemplo que ilustraba dicha explicación, ¿cuál es la diferencia que hay entre el lustrador de zapatos y el filósofo? Ambos son seres humanos iguales, en la medida en que el zapatero, al manejar el cepillo para darle brillo a los zapatos, comprende, en esa utilización, el ser del cepillo. Y el filósofo, en sus quehaceres cotidianos, tales como leer, al leer sin contemplar al libro comprende mejor el ser de dicho instrumento; "Sin embargo, de pronto, en medio de esta indiferencia de la actitud natural, brota en nosotros la pregunta por el ser. Si dejamos que esta pregunta despliegue su fuerza en nuestra vida y que la dirija, asumimos la actitud filosófica y despertamos al filosofar" (Cruz Vélez, 2001, pp. 257-258). Entonces, el filósofo, cual zapatero, le echa cepillo a su capacidad de preguntar, para que brille en su propio ser la manifestación del ser, que yace opacado en la cotidianidad. Según Danilo Cruz Vélez, la actitud filosófica no se trata, entonces, de una reflexión, aunque no explica en qué se diferencia la reflexión del hecho de que en la pregunta del Dasein por el ser haya ya en dicho ser humano una comprensión del ser. Es decir, no explica en qué se diferencia la reflexión del hecho de que, para tratar de contestar la pregunta por el ser, haya que examinar al ser humano, mediante la analítica del Dasein. En otras palabras, para dicho filósofo, el ser es el tema del preguntar filosófico. ¿No es esto, por ende, una variante de la metafísica de la subjetividad? 
Martin Heidegger no muestra en qué se diferencia ese encerramiento en la subjetividad, ese regreso del yo hacia sí mismo, propio de la reflexión, del hecho de que ya sepamos del ser en la actitud natural, aunque no de manera conceptual. Pareciera que todos los seres humanos hubieran llegado a los resultados que el filósofo de la subjetividad logró por medio de mucho esfuerzo mental, interiorizando, pensando en sí mismo, en su propio yo. Sólo que la mayoría de seres humanos no disfruta de esos resultados, es decir, no alardea de su comprensión no conceptual del ser, sino que simplemente la usa para referirse a las cosas, para existir. De esta manera, no se ve claramente en qué consiste la diferencia entre el regresar el yo hacia sí mismo -que es trascender desde la actitud natural hasta la actitud filosófica- y superar el arrojamiento en el mundo, ese estado de caída o despreocupación por el ser propio, que caracteriza a la actitud natural, para trascender a la actitud filosófica, cuando preguntamos por el ser, cuando intentamos tematizarlo y no simplemente operar con él.

En fin, no es clara y distinta -como le gustaba decir a René Descartes- la diferencia entre la tematización de la comprensión del ser que está latente en la naturaleza humana y la reflexión. Aún así, Danilo Cruz Vélez afirma que, partiendo del mundo natural, Martin Heidegger logró salir de la metafísica de la subjetividad. Yo, por mi parte, afirmo que no, a no ser que yo esté confundiendo el significado de la palabra "superar". Como yo lo entiendo, en una carrera de obstáculos tengo dos opciones: o intento superarlo, saltando con esfuerzo sobre él, corriendo el riesgo de tropezarme con el obstáculo y no superarlo, o intento pasar por el lado de él, haciendo trampa. Al hacer esto último, el nombre de "carrera de obstáculos" ya no tiene sentido, pues tiene que ver más bien con una carrera normal de cien metros, por ejemplo, en la cual no hay que saltar. Para mí, Martin Heidegger pasó por el lado del obstáculo de la razón que encumbraron los metafísicos de la subjetividad. Pero siguió en la carrera de obstáculos, siguió en la metafísica de la subjetividad. Sólo que hizo trampa en dicha carrera, al no saltar el obstáculo de la mente como centro y fundamento de todo lo que hay, sino pasarle por el lado, postulando a la afectividad como dicho centro: el ser se revela en el Dasein que siente, en el Dasein que maneja el útil. 
De todas maneras, se puede decir que, a pesar de las similitudes que hay entre Edmund Husserl y Martin Heidegger, hay una diferencia principal entre ellos: aunque Edmund Husserl hizo todo lo posible para librar su filosofía de supuestos, como, por ejemplo, cambiar de camino cada vez que se encontró un supuesto, de todos modos siguió operando con términos de la metafísica de la subjetividad. Mientras que Martin Heidegger se dio cuenta de esos supuestos y los tematizó, realizando así un intento más concienzudo o esforzado de salir de la metafísica de la subjetividad. Que no lo haya logrado es otra cosa. Pero al menos mostró el problema, lo cual es inapreciable, un punto a favor en la obra del más importante filósofo del siglo XX, según Danilo Cruz Vélez. Y de esa diferencia principal se derivan, según el filósofo colombiano, las demás diferencias. Ahora explicitemos, a partir de un fragmento de Filosofía sin supuestos, cómo es que, a partir de esa similitud que hay entre actitud natural y comprensión pre-ontológica del ser, se distancia el pensamiento heideggeriano del husserliano:

Se busca un camino que conduzca al dominio de la filosofía. Se supone, pues, que no se sabe nada de esta. [1] El punto de partida es, por tanto, la situación del hombre antes del aparecimiento de cualquier interés filosófico. Esta situación prefilosófica se caracteriza por lo que Husserl llama la "actitud natural", que es la de la vida cotidiana, en que el hombre está en relación con su mundo circundante [2] representando, juzgando, sintiendo, valorando y queriendo "ingenuamente". En esta relación, en la relación "yo y mi mundo circundante", [3] el yo es un centro de actos que apuntan al mundo. En un primer paso, Husserl acompaña a la vida natural en este movimiento y describe lo que ocurre allí.

Pues bien, en la actitud natural el yo se mueve directamente hacia el mundo, alejándose de sí mismo. Este alejamiento equivale a una [4] enajenación: el yo se pierde en el mundo, olvidándose de sí. Determinado por este olvido, el yo se interesa sólo por el mundo. Este interés determina el contenido de su saber; el cual no es más que un saber mundano. Además, lo sabido en este saber, lo mundano, adquiere el rango de lo que es en verdad. El mundo se convierte así en el modelo de todo ser. Por ello, [5] cuando en esta actitud se avista de algún modo al yo, se lo concibe como una cosa, como algo perteneciente al mundo. De manera que su modo de ser propio queda oculto, ya sea porque la atención no se dirige a él o porque una interpretación mundana lo deforma (Cruz Vélez, 2001, pp. 16-17). 
En esta cita se ve que la husserliana actitud natural contiene algunos rasgos de la heideggeriana comprensión pre-ontológica del ser, al tiempo que contiene unas diferencias importantes. Así, por ejemplo, hay una diferencia radical entre la concepción que tienen Edmund Husserl y Martin Heidegger acerca de la actitud prefilosófica del ser humano, que se da en la cotidianidad. Edmund Husserl no ve nada bueno en ella, razón por la cual la coloca entre paréntesis. Mientras que Martin Heidegger sí la valora, porque considera que en ella debe haber ya una comprensión del ser, aunque dicha comprensión no sea filosófica. Edmund Husserl denomina a ese estado prefilosófico como actitud natural, y parte de dicha actitud para, negándola, llegar a la actitud filosófica; mientras que Martin Heidegger parte de dicha actitud, a la cual denomina como comprensión preontológica del ser, pero no para llegar a una actitud filosófica, poniendo a la actitud natural entre paréntesis, mediante la epojé, como hace Edmund Husserl, sino para tratar de llegar al pensar, que es más propio de los poetas que sienten una gran admiración ante el misterio del ser que de los filósofos posteriores a los presocráticos.

En segundo lugar, en la actitud natural el hombre está en relación con su mundo circundante. Claro que, para Edmund Husserl, quien:

...'tenía una limitación: veía los supuestos únicamente del lado de lo que él llamaba la tendencia objetivista del hombre. Para los supuestos que caen del lado del sujeto no tenía ojos. Él vivía dentro de la metafísica de la subjetividad, y mal podía destruir el suelo de su propia morada. Por esto recibe, sin tematizarlos, los conceptos centrales de dicha metafísica y los emplea como conceptos operativos" (Cruz Vélez, 2001, p. 8).

El orden lógico de esa relación circundante comenzaba con la representación y el juicio. Dicha jerarquía es una de las características principales de la metafísica de la subjetividad. El considerar a lo que no sea yo como objeto, y el pensar que el único campo de comunicación entre esos objetos y yo es la representación, ocurrida en "mi" mente luego de que los sentidos los perciben, es un pilar de dicha metafísica. Pilar que Martin Heidegger va a rechazar, al privilegiar la afectividad -esos sentimientos y esas emociones menospreciadas por la racional metafísica de la subjetividad-como medio originario de relación del Dasein con su mundo (cambia la representación 
por el sentir y la utilización de las cosas). De ahí que no sea contemplando teoréticamente como originariamente me acerco a mi mundo, sino sintiendo alegría, nostalgia o tristeza, por ejemplo. Como lo dice Martin Heidegger, hablando de la constitución existencial del Ahí, en el § 29 de Ser y Tiempo, intitulado El Dasein como disposición afectiva:"En el temple de ánimo, el Dasein ya está siempre afectivamente abierto como aquel ente al que la existencia [Dasein] le ha sido confiada en su ser, un ser que él tiene que ser existiendo. Abierto no quiere decir conocido como tal" (Heidegger, 1927, p. 139).

Así, esta diferencia entre la concepción husserliana de actitud natural y la concepción heideggeriana de comprensión preontológica del ser, radica en que, para Edmund Husserl, la lista según la cual el hombre está en relación con su mundo circundante comienza, como se dijo anteriormente, con las cogitaciones o actividades del pensamiento, a saber: representand o y juzgando. Luego sí sintiendo, valorando y queriendo. Mientras que, de acuerdo a la mentalidad heideggeriana, la lista debería comenzar con las afectividades: sintiendo, valorando, queriendo... utilizando, manejando... y ahí sí, después de todo eso, representando, juzgando. Esta consideración hace parte de lo que para él es la superación de la metafísica de la subjetividad iniciada por René Descartes, de la cual también habla en el § 21. Discusión hermenéutica de la ontología cartesiana del "mundo" de Sery Tiempo, que dice así:"Descartes no sólo ofrece posiblemente una determinación ontológica errada del mundo, sino que su interpretación y los fundamentos de ella conducían a pasar por alto tanto el fenómeno del mundo como el ser del ente intramundano inmediatamente a la mano" (Heidegger, 1927, p. 139).

En tercer lugar, para Edmund Husserl el yo es un centro de actos que apuntan al mundo. Mientras que para Martin Heidegger no hay algo así como un yo. Él critica esa concepción del "yo mismo", del "sujeto". Rechaza esa concepción de yo como aquello que se mantiene idéntico a través de los comportamientos y vivencias, y de esa manera se relaciona con la multiplicidad. También rechaza al yo como aquello que, "dentro de una región cerrada y para ella, ya está siempre y constantemente ahí, como lo que, en un sentido eminente, subyace en el fondo de todo lo demás, es decir, como el subiectum" (Heidegger, 1927, p. 120). Es decir, también rechaza la sustancialidad del alma, la 
cosidad de la conciencia y el carácter de objeto de la persona, como"conductor ontológico para la determinación del ente desde el que se responde a la pregunta por el quién" (p. 120). Y empieza a rechazar esa concepción del yo con la pregunta: " ¿Es acaso evidente a priori que el acceso al Dasein deba ser una simple reflexión perceptiva sobre el yo de los actos?" (p. 120), a la cual no le va a dar una respuesta cerrada: "no", sino que va a contestar mediante la elaboración del concepto de Dasein y la hipótesis de cómo fue que al Dasein se lo llegó a llamar yo, es decir, dará una interpretación existencial del yo en tanto determinación esencial del Dasein. Para Martin Heidegger, más bien, "La indagación dirigida hacia el fenómeno que permite responder a la pregunta por el quién, conduce hacia estructuras del Dasein que son co-originarias con el estar-en-el-mundo: el coestar [Mitsein] y la coexistencia [Mitdasein]. En este modo de ser se funda el modo cotidiano de ser-sí-mismo, cuya explicación hace visible eso que podemos llamar el "sujeto" de la cotidianidad: el "se" o el "uno" [das Man]" (p. 119).

En el § 27 de Ser y Tiempo, intitulado como El ser-sí-mismo cotidiano y el uno, Martin Heidegger cumple la promesa de interpretar al yo existencialmente, para contestar la pregunta por el quién. Luego de haber analizado el "coestar" del Dasein, Martin Heidegger dice que: "que el 'carácter de sujeto' del propio Dasein y del Dasein de los otros se determina existencialmente, esto es, se determina a partir de ciertas formas de ser. En las cosas que nos ocupan en el mundo circundante comparecen los otros como lo que son; y son lo que ellos hacen" (p. 130). Sucede que, entre más trabaja el Dasein con los útiles de su mundo, de su vida cotidiana, entre más se ocupa o cuida de ellos y de su quehacer, más se da su preocupación o cuidado por mantener una diferencia frente a los otros seres humanos. Al tiempo que convive con ellos, se está preocupando o intranquilizando por mantener esa distancia. Como le pasa al profesor de colegio que, conviviendo con sus estudiantes, lo que más le interesa -más, incluso, que enseñar- es que los estudiantes mantengan o conserven esa distancia (estudiante/profesor). Igual se puede decir del jefe con sus obreros o empleados. El caso es que, en la cotidianidad, usualmente, ni el profesor ni el jefe se dan cuenta de que todo el tiempo están marcando y conservando esa diferencia con sus subalternos. $Y$ de esta manera, ese modo de ser del Dasein, ese carácter de distancialidad, opera en el profesor y el jefe de una manera más originaria y tenaz. 
Es ahí cuando uno se pregunta: ¿será que el profesor está siendo lo que es?, ¿el jefe está actuando tal como él es, de acuerdo a su yo? Aunque en otros escenarios, como en la casa, y en otros tipos de relaciones con otros Dasein, como el que el profesor puede tener con su hijo y el jefe con su amigo, tanto el profesor como el jefe ya no estén sometidos a esa presión de mantener a la raya a sus subalternos, de todas maneras siempre buscarán mantener un tipo de distanciamiento en estas relaciones diferentes a las laborales. "Aunque yo te dé confianza, hijo, recuerda que yo soy tu papá" suele decirle el papá a su hijo, independientemente de que dicho papá sea profesor o jefe o carpintero o desempleado. Es decir, de cualquier manera, el profesor, el jefe, el Dasein está sometido a mantener su distanciamiento frente a los otros en cualquier tipo de relación, como lo explica Martin Heidegger.

Ahora bien, esta distancialidad propia del coestar indica que el Dasein está sujeto al dominio de los otros en su convivir cotidiano. No es él mismo quien es; los otros le han tomado el ser. El arbitrio de los otros dispone de las posibilidades cotidianas del Dasein. Pero estos otros no son determinados otros. Por el contrario, cualquier otro puede reemplazarlos. Lo decisivo es tan sólo el inadvertido dominio de los otros, que el Dasein, en cuanto coestar, ya ha aceptado sin darse cuenta. Uno mismo forma parte de los otros y refuerza su poder. "Los otros"-así llamados para ocultar la propia esencial pertenencia a ellos- son los que inmediata y regularmente "existen" ["da sind"] en la convivencia cotidiana. El quién no es éste ni aquél, no es uno mismo, ni algunos, ni la suma de todos. El "quién" es el impersonal, el "se" o el "uno" (p. 130).

Con esta explicación, Martin Heidegger muestra lo absurdo que es concebir al yo en términos de sustancialidad, como una cosa con propiedades. Pues, simplemente, el profesor, en su clase, no está siendo tan tierno y condescendiente con los estudiantes como es con su hijo. Pero eso no significa que se esté poniendo una máscara de teatro, para fingir ser una persona que no es

2 Realizo esta pregunta en términos de yo como "cosa con propiedades", para dar pie a la crítica de Martin Heidegger a dicha cosificación del Dasein. Que el Dasein no es una cosa, es una de sus tesis principales, declarada en contra de la metafísica de la subjetividad. Y con esta idea, podemos mostrar el quinto rasgo de la husserliana actitud natural manifiesta en la heideggeriana comprensión preontológica del ser, con su respectiva diferencia: para Edmund Husserl, el yo es la misma sustancia pensante de Descartes. Para Martin Heidegger, en cambio, el Dasein no es una cosa con propiedades, porque, en primer lugar, no es cosa y, en segundo lugar, no tiene propiedades, al estilo alma-cuerpo, sino que es una integridad, aunque "tenga" modos de ser o existenciales. 
en realidad, pues, de ser así, nos enfrentaríamos a la otra parte del círculo vicioso: el profesor en su casa, no está siendo tan rígido y estricto con su hijo como lo es con sus estudiantes. Círculo que nos lleva a la pregunta: ¿entonces, quién es, a fin de cuentas, Samuel (suponiendo que así se llame el profesor de esos estudiantes y el papá de ese hijo? El yo de Samuel se define, entre otros modos de ser, según el modo de ser de la distancialidad a la cual está sometido en toda relación con cualquier otro Dasein: el profesor es el profesor y el papá es el papá. Esto implica que no hay algo así como un Samuel verdadero (el de la casa) y un Samuel falso (el de la clase). Simplemente, Samuel se comporta, actúa, tal como se lo exige cada tipo de relación: Samuel es profesor cuando trabaja, cuando le toca ser o ejercer sus funciones de profesor, es decir, cuando está frente a sus estudiantes; es papá cuando está frente a su hijo; es compañero cuando está frente a otro profesor en la sala de profesores; es esposo cuando está frente a su esposa. Y no es profesor cuando no está frente a sus estudiantes, ni papá cuando no está frente a su hijo, ni compañero cuando no está frente a otros profesores, ni esposo cuando no está frente a su esposa. Samuel es lo que es, según el tipo de relación que esté manteniendo en los diferentes momentos de su vida, en su propia historicidad, como diría Martin Heidegger. Y esto, por extensión, se puede aplicar a las relaciones de Samuel con los objetos o entes intramundanos de su mundo: es lector cuando está frente al libro, y en ese momento no es ciclista aficionado. Pero cuando se va a pasear en su cicla, en ese momento, no es lector. De ahí que sea el cuidado (Sorge) y no el yo, la esencia o estructura de la existencia humana que recoge en una unidad los diversos elementos del ser-en-el-mundo (Rodríguez García, 2002, p. 213). Estructura de la existencia humana que no se limita a los objetos intramundanos, sino que también concierne a las relaciones del Dasein con sus semejantes. Como dice Martin Heidegger:

Gozamos y nos divertimos como se goza; leemos, vemos y juzgamos sobre literatura y arte como se ve y se juzga; pero también nos apartamos del'montón' como se debe hacer; encontramos 'irritante' lo que se debe encontrar irritante. El uno, que no es nadie determinado y que son todos (pero no como la suma de ellos), prescribe el modo de ser de la cotidianidad (Heidegger, 1927, p. 131). 
Sólo habría que mirar qué tan original es esta crítica heideggeriana al uno impersonal.

\section{Conclusión}

La metafísica de la subjetividad y el intento de superación de la misma llevada a cabo por Martin Heidegger son temas recurrentes, transversales, en la mayoría de textos que Danilo Cruz Vélez escribió después del viaje a Alemania en 1951; temas que en algunos textos da por sentado, como si todo el mundo supiera de qué está hablando, pero que explica detalladamente en textos de suma importancia como Filosofía sin supuestos, de 2001. En dicho libro, que es, en mi opinión, el elaborado con más rigor filosófico, el "libro orgánico" (Cruz Vélez, 2001, p. 19), "la obra más importante por su estructura y sus ambiciones" (p. 21), como decía Rubén Sierra Mejía (sin implicar, con esto, que los demás textos de Danilo Cruz Vélez no tengan rigor filosófico), el filósofo caldense expone el pensamiento de Martin Heidegger. Allí muestra que este último filósofo no se opone necesariamente a la tradición filosófica que lo precedió; no la destruye como algunos críticos han querido hacerlo ver, sino que parte de dicha tradición para superarla. Por esta razón, la primera parte del libro es una exposición del pensamiento de Edmund Husserl y su relación con, entre otros, René Descartes, padre de la filosofía moderna. Mientras que la segunda parte del libro es el distanciamiento que Martin Heidegger toma del pensamiento de su maestro. No se trata de que Martin Heidegger haya renunciado a la fenomenología, sino que trata de renunciar al supuesto principal en el cual todavía dicha corriente filosófica se basaba, a saber: el yo o sujeto como fundamento constituyente de la cosa u objeto. Así, al agotar la metafísica de la subjetividad todas sus posibilidades, Heidegger intenta un nuevo comienzo:

La filosofía ha tenido una floración espléndida a fines del siglo XIX y la primera mitad del siglo XX. Pero sí hay un fin de formas de filosofar. El filosofar es histórico, inicia caminos y los lleva hasta el final, agotando todas las posibilidades de desarrollo de un principio, de una concepción del ser. Se puede hablar, por ejemplo, de un fin del cartesianismo, de lo que se ha llamado la metafísica de la subjetividad; hay un fin de la metafísica de la subjetividad como hay un fin del platonismo. Nietzsche tenía la razón, hay un fin del platonismo, el platonismo 
agotó todas sus posibilidades de desarrollo. Y la metafísica de la subjetividad llegó a la perfección con Husserl, perfección en el sentido de la capacidad de explicar todos los fenómenos. Con la fenomenología constitutiva se llegó hasta lo último en el desarrollo del cartesianismo, de la explicación de toda la realidad partiendo de la subjetividad. De manera que podemos hablar de un fin del platonismo, de un fin de la metafísica de la subjetividad, pero no de un fin de la filosofía... Así que habrá filosofía mientras el hombre sea hombre. Se agotan las posibilidades de un filosofar, es cierto. Usted alude, por ejemplo, a Heidegger en relación con el problema del ser. Heidegger llegó a un callejón sin salida; por ello, no se puede seguir adelante partiendo del punto al que él llegó. Entonces hay que seguir otro camino (Sierra Mejía, 1996, p. 53).

Nuevo comienzo o nuevo camino de la filosofía que consiste, básicamente, en poner al Dasein en lugar del sujeto. Por eso mi valoración crítica radica en afirmar que Martin Heidegger no supera la metafísica de la subjetividad. Más bien elabora un debate serio en el marco de dicha metafísica. Para él, lo primordial para el conocimiento no es la representación sino la afectividad. La racionalidad de los científicos y los filósofos deja de ser el centro del universo, para darle paso a la tristeza, la nostalgia entre cualquier otro sentimiento de cualquier persona del común. Para Martin Heidegger, cualquier persona que se dé cuenta de que su ser es impropio porque está llevando una vida volcada en la cotidianidad, en el quehacer constante que impide un tiempo para la meditación, está invitada a reflexionar sobre ese ser que ya comprende pero que hasta el momento no ha tematizado. Cuando empiece a hacerlo, cuando se ponga en camino, estará cruzando los caminos del bosque que conducen al ser. Los caminos de su propio ser, pues éste se revela en el Dasein mismo. Pero lo importante no es llegar a la meta, sino mantenerse en dicho camino. ¿No es esto Tao? Posiblemente, la novedad del filósofo de la Selva Negra radique en haber incorporado en una metafísica propiamente occidental rasgos característicos de la mística oriental. Posiblemente, tal relación de su pensamiento con el de Oriente haya llevado a su discípulo, Danilo Cruz Vélez, a postular una huída al pueblo, desde donde se puede avistar al campo, ante este mundo que desborda aparatos técnicos que ocupan todo el tiempo de las personas. Sólo en los lugares tranquilos, donde hay serenidad, se puede meditar, interiorizar y trabajar reposadamente en la recuperación del ser propio, mediante la pregunta por el ser. 


\section{Referencias}

Berciano Villalibre, M. (1991). Superación de la metafísica en Martin Heidegger. Oviedo: Servicio de publicaciones - Universidad de Oviedo.

Cruz Vélez, D. (2001). Filosofía sin supuestos (2a. ed.). Manizales: Editorial Universidad de Caldas.

Descartes, R. (1641). Meditaciones acerca de la filosofía primera, en las cuales se demuestra la existencia de Dios, así como la distinción real entre el alma yel cuerpo del hombre. Recuperado el 31 de agosto de 2009 desde <http:// www.inicia.es/de/diego_reina/moderna/rdescartes/meditacion_segunda.ht $>$.

Copleston, F. (1969). Historia de la filosofía (vol. I). Grecia y Roma. Barcelona: Ediciones Ariel S.A. - Esplugues de Llobregat.

Hoyos, L. E. (2003). Filosofía, filosofías, filosofar. En Hoyos, L. E. Lecciones de filosofía, (pp. 12-34). Bogotá: Universidad Externado de Colombia - Universidad Nacional de Colombia.

Ferrater Mora, J. (1965). Diccionario de filosofía. Buenos Aires: Editorial Sudamericana.

Heidegger, M. (1927). Ser y Tiempo. Recuperado el 25 de agosto de 2009 desde <http://www.philosophia.cl/biblioteca/Heidegger/Ser\%20y\%20 Tiempo.pdf $>$.

Heidegger, M. (1934). Lógica. Lecciones de M. Heidegger (semestre verano 1934) en el legado de Helen Weiss, 1991. Barcelona: Editorial Anthropos - Ministerio de Educación y Ciencia.

Rodríguez García, R. (2002). Martin Heidegger y la crisis de la época moderna. Madrid: Ediciones Pedagógicas.

Sierra Mejía, R. (1996). La época de la crisis: conversaciones con Danilo Cruz Vélez. Santiago de Cali: Editorial Universidad del Valle. 